The BDJ News section accepts items that include general news, latest research and diary events that interest our readers. Press releases or articles may be edited, and should include a colour photograph if possible. Please direct your correspondence to the News Editor, Arveen Bajaj at the BDJ, 64 Wimpole Street WIG 8YS or by email to bdj@bda.org

\section{Personal chair appointed}

Dr Jimmy Steele has been given Personal Chair in Oral Health Services Research in Newcastle.

His research is in a range of areas including national epidemiology such as the National Diet and Nutrition survey of the elderly, the 1998 Adult Dental Health Survey and the 2003 Children's Dental Health Survey.

His health services research includes projects in endodontics, resin bonded bridgework and the development of quality of life related outcome measures. He also has a developing interest in research into primary dental care.

Dr Steele studied dentistry in Dundee. He was appointed as lecturer in restorative dentistry in Newcastle in 1989, predominantly working in the conservation department.

Having completed a $\mathrm{PhD}$ in the epidemiology of oral health in the elderly in 1994 and specialist clinical training in restorative dentistry in 1998 he was appointed to a personal senior lecturer post in restorative dentistry in 1999.

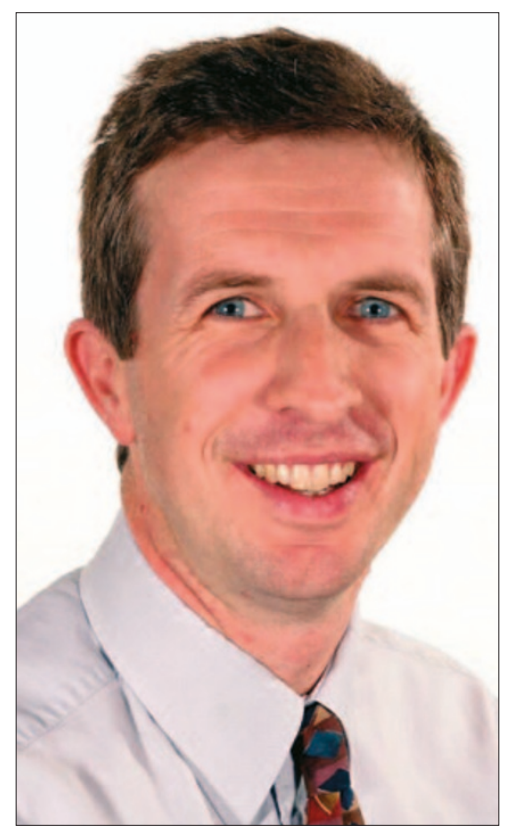

\section{Practice enjoys new success}

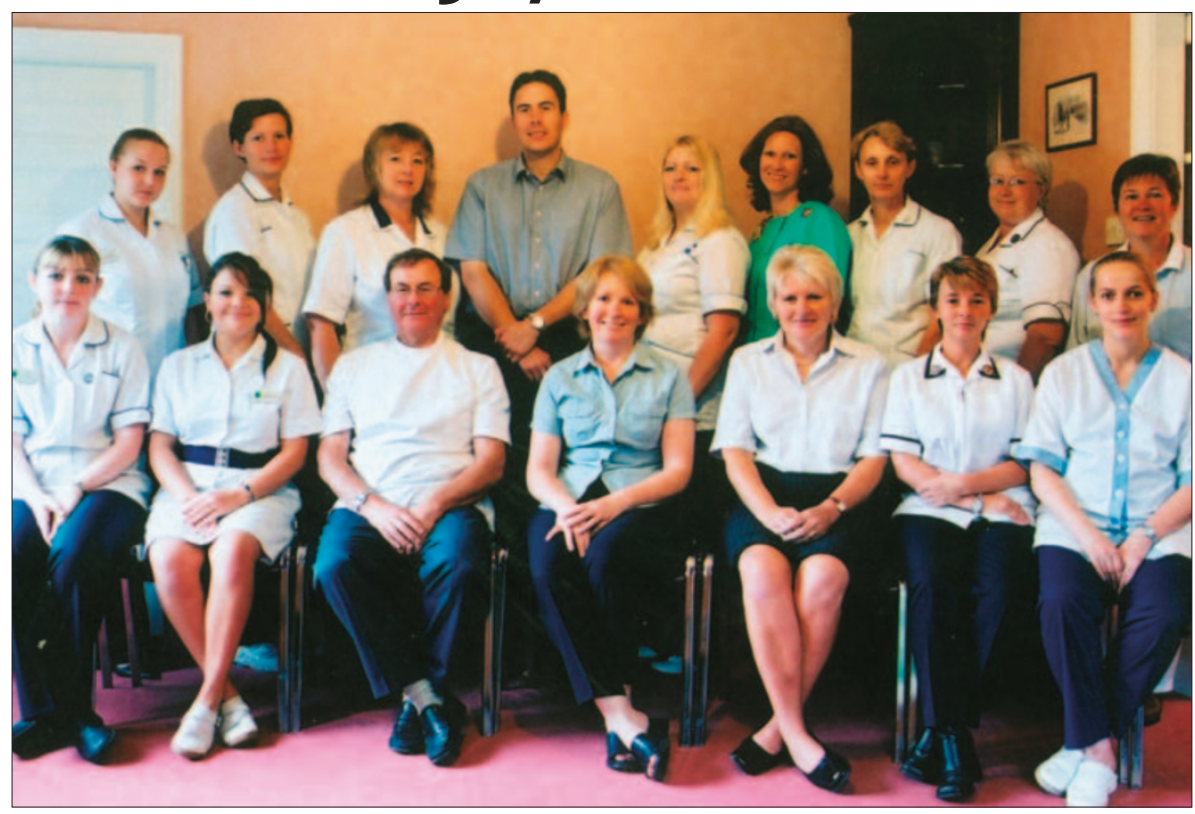

A group of three dental practices in Solihull and Water Orton have been recognised as an Investor in People. Griffin, Griffin \& Associates owned by Dr's Tony and Julia Griffin received the award earlier this year and claim that it has raised awareness among the staff to specific training and development opportunities available to each member.

\section{New oral health strategy launched}

Sunderland Teaching Primary Care Trust recently launched its new Oral Health Strategy, which plans to address dental problems in Sunderland through improved oral health promotion, increasing the number of Sunderland residents registered at dentists and recruiting more dental specialists.

Deputy Chief Dental Officer Barry Cockroft (pictured) plans to take the strategy to other areas across the country as a model of good practice.

In some areas in Sunderland

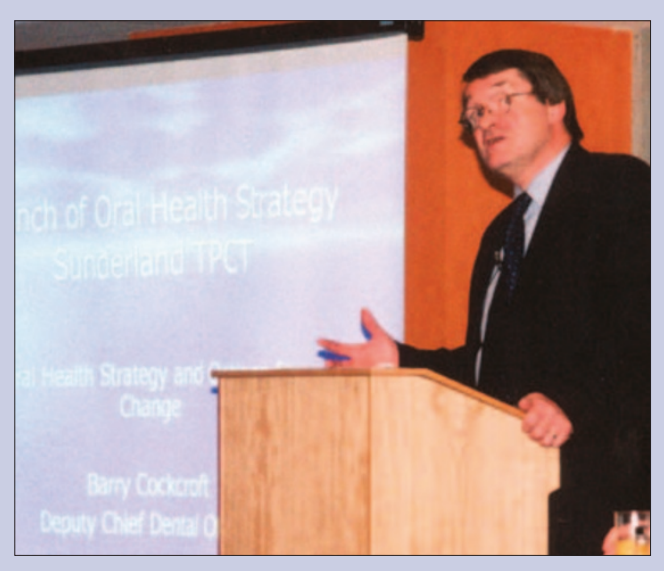
there are significantly higher levels of dental caries and other oral health problems in comparison to regional and national statistics. The number of decayed, missing or filled teeth in some areas of the city has been measured at over twice the national average.

Dental caries and poor oral health in adolescents and adults also stand at high levels. For more information email joanne.walker@suntpct.nhs.uk. 


\section{DIARY}

January 2004

Career opportunities in UK dentistry

Date: 23.01.04

Venue: Institute of Education, London

Contact: Tatyana Stratford, Eastman

Dental Institute

Tel: +44 (0) 2079051244

Email: t.stratford@eastman.ucl.ac.uk

February 2004

16th Annual Mid-Winter Convention

Date: 15-21.02.04

Venue: Almond Beach Village, Barbados

Contact: The Barbados Dental

Association

Tel: 246-228-6488

Email: bdosdentalassoc@caribsurf.com

Website: www.barbadosda.org

Quality Management in Practice

Date: 20.02.04

Venue: British Dental Association,

London

Contact: Kath Blacker, Events office

Tel: +44 (0) 2075634590

Email: events@bda.org

\section{May 2004}

British Dental Conference and Exhibition

Date: 06.05.04 - 08-05.04

Venue: Bournemouth International

Centre

Contact: Events Office,

British Dental Association

Tel: +44 (0) 2075634590

Fax: +44 (0) 2075634591

Email: events@bda.org

\section{Delegates raise surgery funds}

A series of generous donations by delegates at the BDTA Showcase raised enough funds to send a Dentaid surgery to Chad, one of the world's poorest countries.

A draw at the event, sponsored by the Dentists' Provident Society, together with donations from dental companies provided the $£ 3,000$ needed to send equipment to a clinic in the Koumra region of Chad.

The prize draw was for a weekend for two in Paris and was won by Dr Shabir Pandor, a dentist from London.

Dr Eloi, the dentist in Chad, has until now been using a treadle powered drill and very basic equipment to serve a population of three million people. The surgery funded by the Showcase delegates will revolutionise dental care in the area, according to the dental charity.

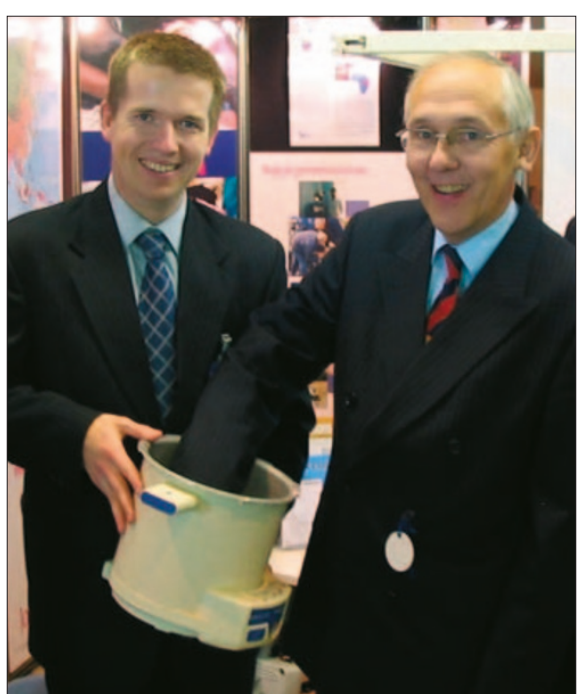

Luke Wordley (left) Chief Executive of Dentaid with lan Passey of Dentists' Provident who sponsored the prize, drawing the winning ticket.

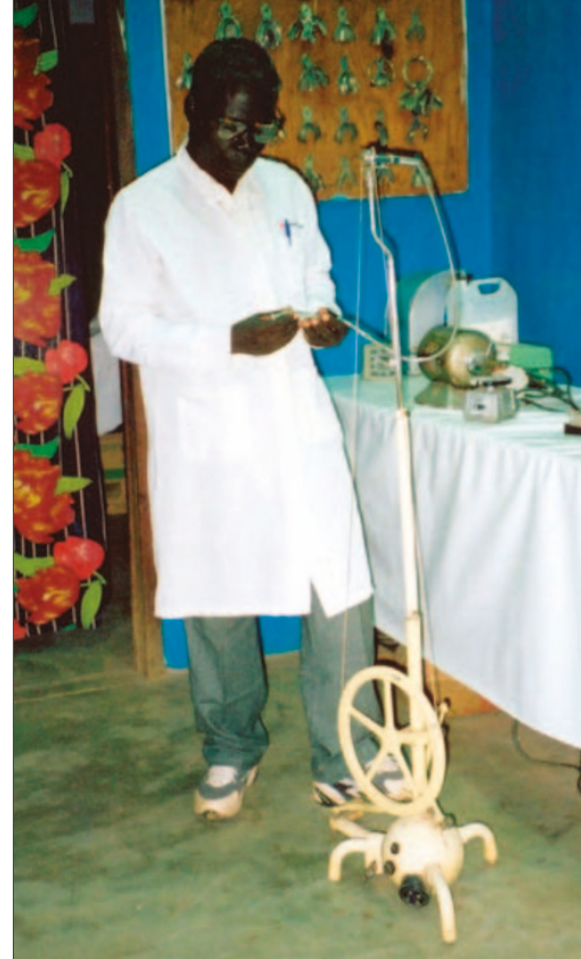

Dr Eloi in his 'surgery' in Chad.

Chad, a large landlocked country in central Africa is one of the world's poorest nations where many have a life expectancy of only 48 years.

With the north of the country in the Sahara desert and the south so wet that the roads are often impassable, it has only 16 dentists in the country, a ratio of 1:500,000.

Two thirds of the 8 million population depend on subsistence agriculture for a living and it has the least industry in equatorial Africa. 


\section{Highland practice achieves liP}

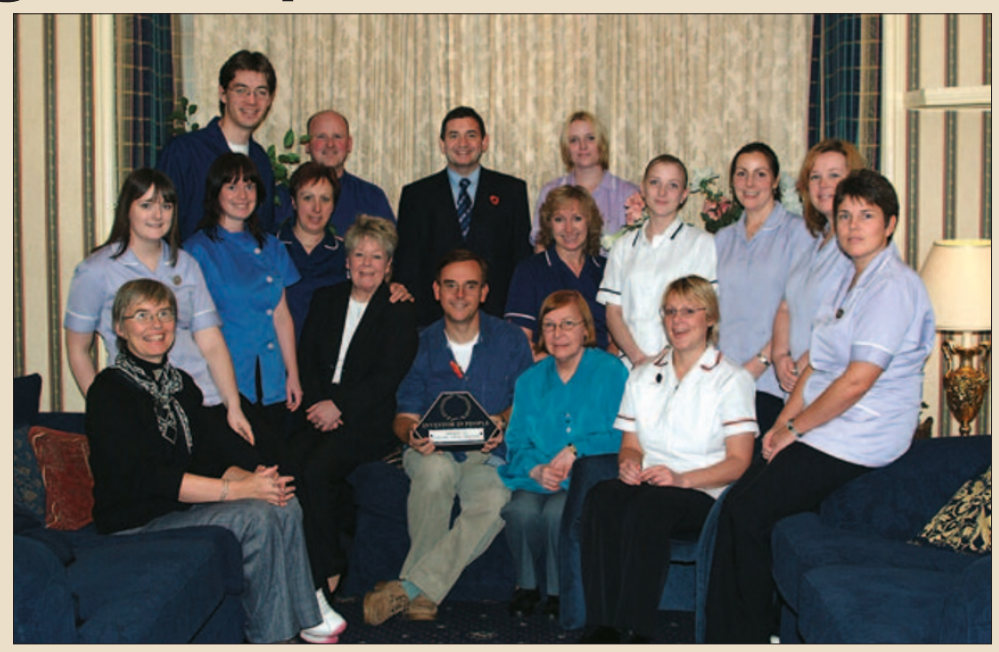

Highland Dental Practices have been recognised as an Investor in People. The liP award recognises a strong culture of training and staff development within the practices which have been approved for postgraduate vocational training. Five dental nurses are registered with the remaining two working towards their SVQ in dental nursing.

\section{FDI elects new science commission chair}

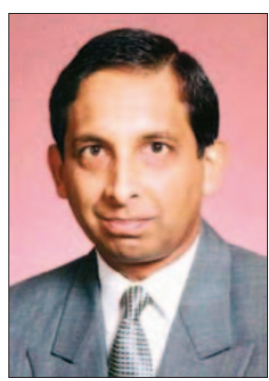

Professor Lakshman (Sam) Samaranayake of the University of Hong Kong was elected by the General Assembly to the Chair of the Science Commission of the International Dental Federation at the recent FDI meeting in Sydney.

In this capacity he will also serve as a councillor and a board member of the FDI. He is the first from the Asian region to be elected to this position and has served the Science Commission since 1998.

His current research interests span both laboratory and clinical studies in oral mycology and infection control in dentistry.

\section{New president installed}

Gary Whittle was installed as President of the Community Dental Services Group for 2003/04 at the organisation's Annual Presidential and Scientific Meeting.

It took place in October at the Manchester Marriott Worsley Park Hotel and Country Club. (Right: Gary Whittle with the 2002/03 President, Carolyn Taylor.)

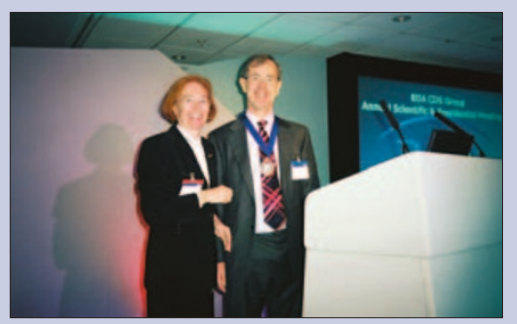

\section{US appointment}

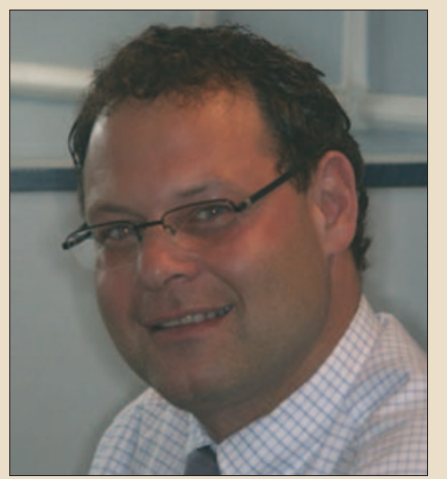

Dr Michael R Norton has been appointed Visiting Professor to the Department of Oral and Maxillofacial Surgery at Marquette University Dental School in Milwaukee, USA.

The appointment was made in recognition of Dr Norton's extensive contribution to the field of implant dentistry and with a view to helping implement a new postgraduate training program in implants.

Marquette recently opened a brand new dental hospital, which features state-of-theart teaching facilities. 